\title{
Inflation derivatives under inflation target regimes
}

\author{
Mordecai Avriel* \\ avriel@ie.technion.ac.il \\ Jens Hilscher ${ }^{\dagger}$ \\ hilscher@brandeis.edu
}

\author{
Alon Raviv $\ddagger$ \\ araviv@brandeis.edu
}

This version: April 2012

\begin{abstract}
Inflation targeting - the central bank practice of attempting to keep inflation levels within fixed bounds around a quantitative target - has been adopted by more than twenty economies. Such practice has an important impact on the stochastic nature of inflation and, consequently, on the pricing of inflation derivatives. We develop a flexible model of inflation targeting in which the central bank's intervention to steer inflation towards the target depends on past deviations and the policymaker's ability or will to enforce the target. We use our model to price inflation derivatives and demonstrate the impact of inflation targeting on derivative pricing.
\end{abstract}

JEL classifications: G12, G13

Keywords: inflation derivatives, inflation targeting, target zones, option pricing

${ }^{*}$ Technion-Israel Institute of Technology, Technion City, Haifa, Israel.

${ }^{\dagger}$ International Business School, Brandeis University, Waltham MA, USA.

${ }^{\ddagger}$ Corresponding author, International Business School, Brandeis University, 415 South Street, Waltham MA 02453, USA. Phone: +1-781-736-2249.

We would like to thank an anonymous referee, Naomi Belfer, Gerald Dwyer, Michael Gofman, Nitzan Regev, Haim Reizman, Monica Singhal, Bob Webb, and seminar participants at Boston University, Brandeis University, the 2008 CRSP Forum, and the 2009 FMA meetings for helpful comments and discussion. 


\section{Introduction}

The global inflation-indexed bond market has grown significantly over the past decade as more governments and corporations have issued inflation-indexed debt. As of 2011, the value of the global inflation-linked bond market reached a total of $\$ 1.8$ trillion. ${ }^{1}$ Most of these bonds, such as those making up the US Treasury inflation protected securities (TIPS) and French OATi market, guarantee a redemption payoff which is equal to the nominal par value and therefore include inflation derivatives in the form of a put option. In addition, a separate market for inflation derivatives has developed in the US, UK, and the Euro area. The payoffs to these derivatives are linked to measures of realized inflation, such as the US consumer price index $(C P I)$ or the UK retail-price-index (RPI).

In this paper we propose a model for pricing inflation derivatives that builds on the intuition of inflation target regimes and that has the flexibility to capture different types of target regimes. Inflation derivative prices depend on the expected future path of inflation, which in turn will be affected by the presence of a target regime. Our model specifically considers how the dynamics of the inflation process depend on specific aspects of target regimes such as speed and aggressiveness of central bank reaction to deviations of inflation from the target. We extend the existing models of inflation derivative pricing, which assume a standard geometric Brownian motion process for inflation (following Black and Scholes, 1973), or assume a meanreverting process (following Vasicek, 1977) and find that our model produces substantially lower pricing errors than either model.

Developing a model for the stochastic process of inflation in the presence of inflation targeting is important given that such policy regimes have been adopted by more than twenty advanced and emerging economies (Roger and Stone, 2005; Heenan et al., 2006). Policy regimes are characterized by an explicit quantitative inflation target, which may be determined by the central bank or given to it in the form of a mandate. The central bank attempts to steer actual inflation towards the target through the use of interest rate changes and other monetary policy

\footnotetext{
${ }^{1}$ See "Inflation-linked bonds: Blossoming markets" (André de Silva, Global Fixed income research, HSBC, 24 November 2011). The inflation derivatives market had a size of $\$ 100 \mathrm{bn}$ in 2011 (Christopher Whittall, International Financing Review, http://www.ifre.com/, 8 March 2012).
} 
tools. The center of the interval or the specific inflation rate targeted currently varies across countries from 1.5 to 2.5 percent per year. The target tends to be a constant yearly yield of the price index (target point) together with a target zone with fixed upper and lower boundaries between which yearly inflation is targeted to remain. Some countries, such as the US, are claimed to be "covert inflation targeters," who unofficially try to target inflation within certain boundaries (Mankiw, 2002). ${ }^{2}$

Inflation targeting has important implications for the pricing of inflation derivatives. We illustrate this point by the following example: a European put option on the $C P I$, with one year to maturity and a strike price that is equal to the current $C P I$ level, will never be exercised if the lower boundary of the target zone is equal to $1 \%$ and the target boundary is perfectly credible. Its price should therefore be equal to zero. In contrast, the price of an at-the-money put option evaluated using a standard Gaussian model, e.g. Black and Scholes (1973), is positive.

As the example illustrates, the degree of credibility of the target zone has important effects on inflation dynamics. Inflation may deviate from the target or lie outside the zone for several reasons. First, there are lags between deviations from the target, resulting changes in monetary policy, and realization of the full impact of policy on the economy (Svensson, 1997). Second, most central banks tend not to choose aggressive attempts to steer actual inflation towards the target since they are trying to avoid reductions in growth and employment (Taylor, 1993). Third, the exchange rate, which may be hit by shocks, affects domestic currency prices of imported goods, which enter into the CPI (Svensson, 2000). It is indeed well documented that deviations from the target are not unusual from an international perspective. Roger and Stone (2005) find that advanced economies miss the target 52 percent of the time on average, and that the average length of inflation exceeding the upper target zone limit is longer than the average time of deviations below the lower limit ( 8.8 and 7.3 months respectively). ${ }^{3}$

\footnotetext{
${ }^{2}$ In January 2012 the US Federal Reserve announced an official inflation target of $2 \%$ (see press release from 25 January 2012, http://www.federalreserve.gov). Previous to this announcement, the Federal Reserve's policy setting committee stated a desired target range for inflation (usually around $1.5-2 \%)$.

${ }^{3}$ There is also substantial cross-country variation in the average time of deviation from the target. While in Thailand and South Korea the rate of inflation deviates from its target only $2 \%$ and $5 \%$ of
} 
We develop a general continuous time model for the inflation process in which the central bank intervenes to keep inflation close to the target. Central bank intervention depends on the economy's record of past deviations from the target. This record is captured by a state variable that accumulates the weighted average of past deviations. As the absolute value of this state variable increases, its effect on the drift term and the diffusion coefficient of the $C P I$ process increases. The effect of each past deviation from the target zone on the inflation state variable is a function of its distance from the present as well as the size of the deviation. The model can incorporate both strong and less aggressive policy reactions to inflation deviations, and therefore different levels of inflation target credibility. The model can capture different empirical aspects of the inflation process that are typical for target regimes, where the credibility of interventions may be limited and deviations from the boundaries can occur.

We illustrate the effect of our model on inflation derivative prices and formalize the intuition of why inflation dynamics in a target regime produce option prices that are different from those predicted by the Black and Scholes (1973) model. Numerical examples are provided in order to evaluate how the maturity of the contract, moneyness of the option, volatility of the $C P I$, and parameters of the model affect the value of inflation derivatives. We consider differences in the speed with which policy reacts to inflation deviations as well as policy effectiveness. Furthermore, we show that our model can match the volatility skew that is common in most inflation derivative markets (that is, implied volatility is not constant across different strike prices).

Finally, we fit our model to market prices of long-dated US inflation caps and show that the target model has lower pricing errors than the Black and Scholes (1973), mean-reverting (Vasicek, 1977), and two-factor stochastic volatility (Hull and White, 1988; Heston, 1993) models. Target model absolute pricing errors are low across different strike prices and for different maturities. Relative to Black and Scholes, our model cuts the total absolute pricing error almost in half. Implementing a simple mean reverting (Vasicek) model does not improve

the time respectively, in Israel and in the Czech Republic deviations account for $94.4 \%$ and $76.2 \%$ of the time respectively (Roger and Stone, 2005). 
pricing relative to Black and Scholes, while a stochastic volatility model results in a total pricing error that is similar to (though slightly larger than) the target model pricing error.

The remainder of the paper is organized as follows: Section 2 relates the target model to the literature on optimal monetary policy, inflation derivative pricing, valuation models for currency derivatives under target zone regimes, and macroeconomic factor models. Section 3 introduces the model and discusses how it can incorporate several different aspects of the stochastic process of inflation under a target regime. Section 4 implements the target model numerically, compares target model and Black and Scholes (1973) prices, and discusses the intuition of patterns in model prices. We also analyze the ability of the model to explain variation in market prices. Section 5 concludes.

\section{Related literature}

Our target model is related to the wider literature on the reasons for the desirability of inflation targeting. The seminal work by Kydland and Prescott (1977) points out the "time inconsistency" problem. In the context of monetary policy, the central bank may want to choose policy that results in a higher level of inflation than expected by economic agents. This difficulty is a primary motivation for the appointment of an independent central bank (Rogoff, 1985). However, even an independent monetary authority may have a suboptimally high level of discretion and may be subject to political pressure (e.g. Meltzer, 2010). An inflation targeting regime may enhance credibility and reduce uncertainty about future policy, thus anchoring inflation expectations (Svensson, 1997). In our model we assume that the central bank has a certain level of credibility: it may respond strongly and quickly or implement less aggressive policy with longer delays (for example because of differing relative weights on output stabilization and hitting the inflation target). However, the model does not account for the case where the central bank's policy response function itself is time varying, for example due to increased political pressure during times of crisis, or the case where the central bank's inflation target changes over time. 


\subsection{Inflation derivative pricing}

We next briefly review how our target model builds on and differs from the existing literature on inflation derivative pricing. Bodie (1990) first applies the standard Black and Scholes (1973) formula to price $C P I$-linked options by using a foreign exchange analogy as introduced by Garman and Kohlhagen (1983). Real prices (inflation adjusted) correspond to prices in foreign currency, whereas nominal prices correspond to domestic prices in local currency, and the $C P I$ corresponds to the spot exchange rate and follows a lognormal process. Jarrow and Yildirim (2003) compute the price of $C P I$ options when both the real and nominal term structures are stochastic by using a three factor model following Heath, Jarrow, and Morton (1992). In their model, the price level process is exogenous and follows a log-normal distribution.

The assumption of log-normality for the dynamics of the inflation index, though technically convenient, does not find justification in markets (e.g. Mercurio and Moreni, 2006; Kenyon, 2008). In fact, markets for inflation derivatives exhibit a strong volatility skew or smile, implying that log index returns deviate from normality and suggesting the use of skewed and fat-tailed distributions. Ways to relax the assumption of log-normality include introducing stochastic volatility (Haastrecht and Pelsser, 2011; Mercurio 2005) or jump diffusion processes (Hinnerich, 2008). While such models provide an elegant and computationally effective way for pricing inflation derivatives, they lack a deeper economic underpinning. In contrast, our model reflects the common practice of inflation targeting while also capturing the volatility skew observed in the data.

\subsection{Exchange rate targeting versus inflation targeting}

The approach of the foreign exchange derivatives pricing literature is also related to our target model. Specifically, inflation targeting has parallels to foreign exchange target zones. To given an example, under the European Monetary System (EMS), a system of fixed exchange rates in effect between 1979 and 1999 (previous to the introduction of the common currency), exchange rates could fluctuate freely only between a lower and an upper threshold. Such targets affect the pricing of derivatives, in particular if their strike price was close to the boundary of the 
target zone.

We can classify exchange rate targeting models into two main categories and characterize their differences by comparing the assumptions they make about the dynamics of exchange rates through assumptions about the drift (trend) and the diffusion (volatility) of the process. The first, based on the seminal contribution of Krugman (1991), assumes that the target zone is perfectly credible; as the exchange rate approaches the boundary, the diffusion coefficient becomes small and the drift drives the process away from the boundary (see Larsen and Sorensen, 2007; Avriel, Bar Shavit, and Reisman, 1998; and Dumas, Jennergren, and Näslund, 1993). The second group of models incorporate the possibility of stochastic realignments of the exchange rate target zone, where the probability of realignment increases when the exchange rate is near a boundary (see Dumas, Jennergren, and Näslund, 1995; Svensson, 1993; Ball and Roma, 1993; Christensen, Lando, and Miltersen, 1999; and De Jong, Drost, and Werker, 2001).

Although the models for pricing currency derivatives under target zone regimes may serve as a starting point for pricing inflation derivatives, there are important differences and thus these models cannot be applied directly. Deviations from the inflation target are common (Roger and Stone, 2005) and therefore models with fully credible targets may not be appropriate. In addition, using a pricing model with the opportunity of realignments of the target does not reflect the behavior of a central bank, since a deviation of inflation from its target does not generally result in a change of the inflation target itself.

\subsection{Macroeconomic factors and derivative pricing}

The paper also adds to the literature relating macroeconomic factors to inflation derivatives pricing. Lioui and Poncet (2004) build a general equilibrium model of a continuous time monetary economy with an endogenous price level that is affected by both real and nominal shocks. Belgrade, Benhamou, and Koehler (2004) examine the effect on inflation derivatives of developing a model that reflects the empirical seasonality of the CPI. Bhansali, Dorsten, and Wise (2009) propose a nominal interest rate model in which the interest rate depends on the process of the output gap and inflation, both following mean reverting processes around different target levels. They do not, however, use their framework for pricing inflation derivatives; 
moreover, unlike our paper, their model does not take deviations from the target inflation rate into account.

\section{The target model}

In this section we introduce our general pricing model for inflation derivatives under an inflation target regime. Our pricing model can account for different central bank reactions to deviations from the target as well as different degrees of control of monetary policy over inflation. We can thereby capture the following common features that are typical to inflation target regimes:

1. The existence of a "soft" floor or ceiling. According to our model inflation can breach the officially declared boundaries of the target zone.

2. Policymakers can respond to inflation within the target zone and respond more aggressively if inflation lies outside the target zone.

3. More recent and repeated deviations of inflation from the target can result in more aggressive responses of policymakers.

4. More severe deviations from the target can lead to more aggressive policy responses.

5. The dynamics of inflation can be mean reverting around the target.

6. The reaction functions below and above the target zone can be different (similar to Bhansali, Dorsten, and Wise, 2009).

As we present the model we refer back to the different aspects of the inflation targeting regimes that our model is able to capture.

Our approach is to specify the stochastic process of the $C P I$ and model the intervention policy of the central bank implicitly, similar to the approach followed by models for foreign exchange derivatives pricing (discussed in the previous section). Our model represents extensions of previously proposed models, which we now discuss briefly in order to show why they do not capture specific unique characteristics of the inflation process resulting from inflation targeting. 


\subsection{Geometric Brownian Motion (Black and Scholes, 1973)}

The standard method for pricing derivatives on the $C P I$ is to use the foreign currency analogy and to assume that the stochastic process followed by the foreign currency is the same as that of a stock providing a known dividend yield (Garman and Kohlhagen, 1983). The drift of the foreign currency under the risk neutral measure is equal to the difference between the nominal domestic and foreign risk-free interest rates. When modeling the evolution of the $C P I$, real prices (inflation adjusted) correspond to prices in foreign currency, nominal prices correspond to domestic prices in local currency, and the $C P I$ corresponds to the spot exchange rate. Therefore, by analogy, the $C P I$ has a drift rate of $\left(r_{f t}-r_{r t}\right)$, where $r_{f t}$ is the instantaneous nominal forward rate and $r_{r t}$ is the instantaneous real forward rate.

Making the standard geometric Brownian motion assumption, the process for $P_{t}-$ the price at time $t$ of one unit of the $C P I-$ is of the form:

$$
\frac{d P_{t}}{P_{t}}=\left(r_{f t}-r_{r t}\right) d t+\sigma_{p} d W_{p}
$$

where $\sigma_{p}$ is the volatility of the $C P I$ return and $d W_{p}$ is a standard Wiener process. Black and Scholes (1973) consider the pricing of derivatives for the special case where interest rates are assumed to be constant.

\subsection{Mean reverting (Vasicek, 1977)}

The standard process in (1) does not consider the existence of an inflation target zone, in which the central bank establishes an explicit quantitative target. Under such a target regime the change of the $C P I$ over a period $\tau$ should be located between a lower and an upper boundary. These boundaries are usually defined symmetrically around a central target $(M)$, such that inflation over the specified period $\tau$ (usually one year) does not deviate from the target by more than a certain percentage $z$. Denoting the accumulated inflation rate as $X_{t}=\frac{P_{t}}{P_{t-\tau}}-1$ we can write the target zone condition as:

$$
M-z \leqslant X_{t} \leqslant M+z \text {. }
$$


If the central bank policy has a simple mean reverting effect on the $C P I$, its stochastic process can be depicted by some version of the Vasicek (1977) model:

$$
\frac{d P_{t}}{P_{t}}=\left[M+\gamma\left(M-X_{t}\right)\right] d t+\sigma_{p} d W_{p}
$$

where the parameter $\gamma>0$ governs the speed of adjustment and is positive to ensure stability around the target. However, such a mean reverting process does not ensure that inflation stays within the upper and lower boundaries of the target zone.

\subsection{Perfectly credible boundaries}

In the context of perfectly credible fixed exchange rate regimes, De Jong, Drost, and Werker (2001), Larsen and Sorensen (2007), and Avriel, Bar Shavit, and Reisman (1998) assume that when the exchange rate (or in our case the accumulated inflation, $X_{t}$ ) is close to the boundaries $(M-z, M+z)$, the diffusion coefficient becomes small and the drift drives the process away from these boundaries. Integrating the Avriel et al. (1998) diffusion coefficient into the mean reverting process from (2) implies the following process for the $C P I$ :

$$
\frac{d P_{t}}{P_{t}}=\left[M+\gamma\left(M-X_{t}\right)\right] d t+\sigma_{p} Y\left(X_{t}\right) d W_{p}
$$

where

$$
Y\left(X_{t}\right)=\left\{\begin{array}{cc}
\frac{\left[X_{t}-(M-z)\right][(M+z)-X]}{z^{2}} & (M-z) \leqslant X_{t} \leqslant(M+z) \\
0 & \text { Otherwise }
\end{array}\right\} .
$$

The diffusion term reaches its maximum when accumulated inflation is at the midpoint of the target zone (if $X_{t}=M, Y\left(X_{t}\right)=1$, the process is the same as the mean reverting case). When the process gets near the target zone boundaries the diffusion coefficient becomes negligible compared to the drift and thus the boundaries are perfectly credible.

An important assumption of the currency target zone models is the fixed range of the exchange rate resulting from the credible and predetermined boundaries: the exchange rate cannot lie above the upper or below the lower threshold. We next relax this assumption. 


\subsection{Inflation target zone model}

We introduce the inflation state variable $F(t, X(t), M, z)$ which accumulates the history of deviations of inflation from the mid-point of the target zone, $M$. The state variable affects the drift of the inflation process, which we assume to be equal to $\left(r_{f t}-r_{r t}\right)+F\left(t, X_{t}, M, z\right)$. When inflation is above $M$, the state variable accumulates negative values and the drift is decreased, while the opposite is true if inflation lies below $M$. This adjustment means that the $C P I$ process reverts to the mid-point of the target zone. Specifically, the state variable is defined as:

$$
F\left(t, X_{t}, M, z\right)=\frac{\int_{0}^{t} e^{-\beta_{2}(t-s)} g\left(X_{s}\right) d s}{\int_{0}^{t} e^{-\beta_{2}(t-s)} d s}-\frac{\int_{0}^{t} e^{-\beta_{1}(t-s)} f\left(X_{s}\right) d s}{\int_{0}^{t} e^{-\beta_{1}(t-s)}} .
$$

Deviations of inflation from the target are captured by the functions $f\left(X_{t}\right)$ and $g\left(X_{t}\right)$, which depend on the inflation rate. The parameters $\beta_{1} \geqslant 0$ and $\beta_{2} \geqslant 0$ govern the relative weight of recent and past deviations from the target. The functions $f\left(X_{t}\right)$ and $g\left(X_{t}\right)$ are defined as:

$$
\begin{gathered}
f\left(X_{t}\right)=\left\{\begin{array}{cc}
\gamma_{1} z+\gamma_{2}\left(X_{t}-M+z\right) & X_{t}>M+z \\
\gamma_{1}\left(X_{1}-M\right) & z+M \geqslant X_{t}>M \\
0 & M \geqslant X_{t}
\end{array}\right\} \\
g\left(X_{t}\right)=\left\{\begin{array}{cc}
0 & X_{t} \geqslant M \\
\delta_{1}\left(M-X_{t}\right) & M>X_{t} \geqslant M-z \\
\delta_{1} z+\delta_{2}\left(M-z-X_{t}\right) & M-z>X_{t}
\end{array}\right\} .
\end{gathered}
$$

where $\gamma_{2} \geqslant \gamma_{1} \geqslant 0$ and $\delta_{2} \geqslant \delta_{1} \geqslant 0$ determine the relative impact on the inflation state variable of deviations above $(\gamma)$ and below $(\delta)$ as well as inside (1) and outside (2) of the target zone. By defining two distinct functions for positive and negative deviations from the target, we allow for the possibility of different reaction functions of the central bank in response to "too high' and 'too low' levels of inflation.

The severity or aggressiveness of the central bank's reaction to a unit increase in the deviation above and below the target $M$ is represented by the parameters $\gamma_{1}$ and $\delta_{1}$ respectively. As $\gamma_{1}$ and $\delta_{1}$ increase, the functions $f\left(X_{t}\right)$ and $g\left(X_{t}\right)$ become more sensitive to differences between $X_{t}$ (inflation) and $M$ (target). The marginal effect of deviations outside of the target 
zone is represented by the parameters $\gamma_{2}$ and $\delta_{2}$. If $\gamma_{2}>\gamma_{1}$ and $\delta_{2}>\delta_{1}$, deviations outside of the target zone have a higher marginal effect on the state variable than deviations inside the target zone, i.e. the central bank acts more aggressively to influence the $C P I$ process in cases where inflation has crossed the target zone boundaries than in situations where inflation is within the target zone. When these parameters are set equal $\left(\gamma_{1}=\gamma_{2}, \delta_{1}=\delta_{2}\right)$, the central bank takes into account only deviations from the center of the target $(M)$ but does not take into account the target zone boundaries.

The inflation state variable depends not only on the most recent inflation rate but also on past levels of inflation. The economic rationale for this assumption is that there may be lags between deviations of inflation from the target and changes in central bank policy, both because it takes time for the central bank to change its policy in response to news about inflation and because there is a lag between policy changes and effects on inflation. The effect of inflation deviations on the inflation state variable can capture these dynamics: as the number of positive deviations increases the state variable decreases, while a series of negative deviations results in an increase of the state variable. Consequently, accumulated deviations result in a more pronounced change in policy and a subsequently larger change in inflation through an increased speed of reversion to the target $M$.

The relative impact of recent and past deviations depends on $\beta_{1}$ and $\beta_{2}$. Since both are assumed to be positive, recent deviations from the target zone have a greater impact on the drift than do remote deviations. However, when these parameters are set to zero, each past deviation has the same effect on the inflation target state variable; $\beta_{1}$ and $\beta_{2}$ are therefore decay factors that govern the relative weight of previous deviations of inflation from the target. High levels of $\beta$ mean that the inflation process depends mainly on the most recent inflation rate, while a low level of $\beta$ results in a close to equal weight of past deviations.

In addition to its effect on the drift, the inflation state variable also affects the diffusion of the process, as described in the following equation for the stochastic process:

$$
\frac{d P_{t}}{P_{t}}=\left[r_{f t}-r_{r t}+F\left(t, X_{t}, M, z\right)\right] d t+\sigma_{p} e^{-\alpha\left|F\left(t, X_{t}, M, z\right)\right|} d W_{p}
$$

The process allows for a higher absolute value of accumulated inflation deviations (above or 
below the target) resulting in lower volatility. This ensures that large and extended deviations from the target result in more direct reversion back to the target. The parameter $\alpha$ determines the magnitude of the effect of the inflation state variable on volatility. Higher levels of $\alpha$ result in lower levels of volatility: that is, a higher level of effectiveness of central bank intervention policy.

\subsubsection{Summary of target model parameters}

We now summarize the different target model parameters:

$\gamma_{1}, \gamma_{2}, \delta_{1}, \delta_{2}$ : Strength of reaction to inflation deviations. Higher levels of these parameters imply a higher likelihood of inflation lying within the target zone or close to the target. Effects of inflation deviations may be different within $\left(\gamma_{1}, \delta_{1}\right)$ and outside $\left(\gamma_{2}, \delta_{2}\right)$ of the target zone as well as for inflation deviations above $\left(\gamma_{1}, \gamma_{2}\right)$ and below $\left(\delta_{1}, \delta_{2}\right)$ the target.

$\sigma$ : Volatility of inflation close to the target.

$\boldsymbol{\beta}_{1}, \boldsymbol{\beta}_{2}$ : Decay of reaction that depends on past inflation deviations. Low levels of $\beta$ mean that the inflation process depends on several recent deviations, implying a lag between past deviations and current levels of inflation. High levels of $\beta$ mean that the process depends primarily on recent inflation deviations. There may be differences between deviations above $\left(\beta_{1}\right)$ and below $\left(\beta_{2}\right)$ the target.

$\boldsymbol{\alpha}$ : Effectiveness of reaction to inflation deviations. High levels of $\alpha$ imply that the volatility of inflation declines with large past deviations of inflation from the target. In this case reactions to past deviations of inflation, in the form of changes in the inflation drift, are more effective at bringing inflation back to the target.

\subsubsection{Special cases}

Our model can incorporate several previous contributions of the literature as special cases.

CASE 1: When $\delta_{1}=\delta_{2}=0$ and $\gamma_{1}=\gamma_{2}=0$ the inflation state variable is equal to zero. The inflation process is therefore no longer mean reverting. The model is reduced to the currency derivative pricing model of Garman and Kohlhagen (1983), discussed above as the case of Black and Scholes (1973). 
CASE 2: When $\alpha=0$ there is no effect of the inflation state variable on the diffusion and if $\beta_{1}=\beta_{2} \approx \infty$ the past inflation history does not enter the inflation state variable. Instead, only the most recent level of inflation is taken into account and the process is thus mean reverting. However, the mean reversion speed may be different within and outside of the target zone as well as for deviations above and below the target.

CASE 2a: A special case of the mean reverting process is if, in addition to the CASE 2 restrictions, $\delta_{1}=\delta_{2}=\gamma_{1}=\gamma_{2}$. In this case the target model is the same as Vasicek (1977).

CASE 3: When $\alpha \approx \infty$, and all the other model parameters are positive, the diffusion term is negligible and the process is governed only by the drift term.

\section{Pricing inflation derivatives}

In this section we use the target model to price inflation options. We analyze prices of caplet and floorlet (European call and put options) in the presence of central bank involvement and a soft target zone (as described in the previous section). We calculate option prices in the target model and analyze the effect on option prices of changing different model parameters. We demonstrate that our model produces different patterns in option prices than the Black and Scholes (1973) model and discuss the intuition underlying these differences. We also compare the ability of our model to match market prices and find that target model pricing errors are lower than in the Black and Scholes (1973) and Vasicek (1977) models and similar to pricing errors in a stochastic volatility model (Hull and White, 1988; Heston, 1993).

\subsection{Caplet and floorlet prices}

We consider caplet and floorlet prices with varying strikes and maturities. A caplet is an option that provides a positive payoff if inflation is higher than a pre-determined level, while a floorlet pays off if at maturity inflation is lower than a pre-determined level. The standard payoff of caplets and floorlets is in terms of the relative change of the price index from a reference date to maturity (inflation over the life of the contract), compared to the level given by a fixed rate (strike price). At maturity of the option the payoffs to inflation caplets and floorlets are equal 
to:

$$
\begin{gathered}
\text { Caplet }=\left(\frac{C P I_{T}}{C P I_{T_{0}}}-(1+K)^{\left(T-T_{0}\right)}\right)^{+} \\
\text {Floorlet }=\left((1+K)^{\left(T-T_{0}\right)}-\frac{C P I_{T}}{C P I_{T_{0}}}\right)^{+}
\end{gathered}
$$

where $C P I_{T_{0}}$ is the value of the $C P I$ at time $T_{0}, C P I_{T}$ is the value of the $C P I$ at expiration $T$, and $K$ is the strike price. The prices of the options are equal to the expected discounted cash flows under the risk-neutral probability measure $Q$ :

$$
\begin{gathered}
\text { Caplet }(t)=E_{t}^{Q}\left(\frac{C P I_{T}}{C P I_{T_{0}}}-(1+K)^{\left(T-T_{0}\right)}\right)^{+} e^{-\int_{t}^{T} r_{f s} d s} \\
\text { Floorlet }(t)=E_{t}^{Q}\left((1+K)^{\left(T-T_{0}\right)}-\frac{C P I_{T}}{C P I_{T_{0}}}\right)^{+} e^{-\int_{t}^{T} r_{f s} d s .}
\end{gathered}
$$

\subsection{Calibration of target model prices and sensitivity analysis}

In order to illustrate the different features of our model we present numerical examples of option prices. We compare target model prices using our model process for inflation from (6) to Black and Scholes (1973) prices, which assumes the inflation process from (1). Since there is in general no analytical solution for option prices in the target model we solve for prices numerically by calculating option prices based on Monte-Carlo simulations. ${ }^{4}$

We assume that the inflation rate before the valuation date was constant and equal to the target $M$, which we assume to be $2 \%$. We assume that the distance between the center of the target zone $(M)$ and its boundaries is $z=1 \%$ so that the width of the target zone is $2 \%$. This target zone is typical for advanced economies and exists in Canada, the UK, Israel, and Sweden. The volatility of the CPI yield is equal to $2 \%$, based on the average rate of advanced and emerging economies. Options on the $C P I$ are embedded in many long-term swap contracts; we therefore consider one and three year maturities, significantly longer than the typical stock option. The risk-free rate is set equal to $r_{f}=5 \%$, the real rate is $r_{r}=3 \%$

\footnotetext{
${ }^{4}$ For each valuation of the CPI we use 40,000 sample paths. We have checked that this number of simulations produces stable prices.
} 
and both are assumed to be constant. The target zone parameters are set to: $\gamma_{1}=\delta_{1}=0.3$, $\gamma_{2}=\delta_{2}=0.6$. We assume that $\alpha=40$ (the effectiveness of policy reactions to past inflation deviations) and that $\beta_{1}=\beta_{2}$. We consider different levels of $\beta$ (the decay parameter governing the reaction to past deviations of inflation from the target). Specifically we choose the case of equal weights $(\beta=0)$, an intermediate level $(\beta=3)$, which we refer to as the "base case," and the case where only the most recent observation is taken into account $(\beta \approx \infty)$.

The parameters imply the following effects: (1) The reaction of the central bank to a marginal increase in inflation is twice as large for inflation deviations outside the target zone than it is for deviations of inflation located inside the target zone. (2) The reaction function is identical for overshooting and undershooting of the target. (3) The effect of past deviations on the reaction function is constant across recent and past deviations $(\beta=0)$, is decreased as we go backward in time $(\beta>0)$, or focuses only on the most recent deviation $(\beta \approx \infty)$. (4) The diffusion term decreases as the inflation target state variable increases $(\alpha>0)$. The $C P I$ value is normalized at time $T_{0}$ to one $\left(P_{t}=1\right)$.

\subsubsection{Caplet prices}

Table I reports caplet prices according to the target model. We consider five strike prices chosen to be symmetric around the midpoint of the target $(2 \%), 0.99,1.01,1.02,1.03,1.05$ for a maturity of 1 year (Panel A) and 1.01, 1.03, 1.06, 1.09, 1.11 for a maturity of 3 years (Panel B). Since inflation has a positive average drift we choose a higher set of strike prices for the three year maturity (if we assume that the drift is equal to $2 \%$, we expect the price index to increase from 1 to 1.02 over 1 year and from 1 to $1.02^{3}=1.06$ over 3 years). The strike prices in the table thus allow us to observe the effect of our model on inflation realizations within and outside of the target zone. We also consider two levels of volatility, $2 \%$ and $6 \%$. In addition to prices calculated using the target zone model, for each strike price, volatility, and maturity combination we also report Black and Scholes (B\&S) option premia.

The main difference between the target model and the B\&S model is the relative likelihood of extremely high and extremely low realizations of inflation, in particular inflation levels that lie outside of the target zone. Such levels of inflation will prompt central bank action resulting 
in inflation moving back toward the target and back within the target zone.

Consequently, in the target model realizations of inflation close to the target are relatively more likely than they are for B\&S. In particular, the probability of high realizations of inflation are lower in the target model, reducing the expected payoff of the caplet at maturity (and decreasing the price relative to $\mathrm{B} \& \mathrm{~S})$. Consistent with this intuition, B\&S prices are significantly larger for caplets with strike prices that are above the target. For example, the target model price of a caplet with strike price of 1.03 (and maturity of 1 year and volatility of $2 \%$ ) is 0.18 , far below the B\&S price of 0.40. The lower target model caplet price reflects the reduced probability of inflation realizations above the upper limit of the target zone (1.03).

Caplet prices also depend on low realizations of inflation, which are less likely under the target model. This effect means that as the strike price decreases below the midpoint of the target, the difference between target model caplet and B\&S prices declines. The price of a caplet with a strike price of 0.99 is 2.84 (target zone), almost equal to the B\&S price of 2.93.

Effects are similar for 3-year maturity options. The target model price is 4.40 for a caplet with a strike price of 1.01 and a $2 \%$ volatility, very close to the B\&S price of 4.56 . For a strike price of 1.09, for which realizations of inflation above the target are important, the target model price is 0.05 , much smaller than the B\&S price of 0.42 .

We also consider the effect of a higher level of volatility. In both panels we report target model and B\&S prices assuming that $\sigma=6 \%$. As before, model prices lie below B\&S prices and differences are larger for high strike prices since, relative to B\&S, the target model continues to result in lower probabilities of extremely high levels of inflation. For low strike prices we now also see large differences in price. The reason for this is the much higher probability of high (and above target zone) levels of inflation in the case of $\mathrm{B} \& \mathrm{~S}$.

The inflation deviation decay parameter $(\beta)$ also affects caplet prices. We expect $\beta$ to have the strongest effect on central bank policy for inflation rates outside of the target since it is for these deviations that shifting the relative weights placed on different inflation lags has the largest impact. Consistent with this intuition, caplet prices vary most across different levels of $\beta$ when the strike price is high, volatility is high, or maturity is long; that is, when caplet prices depend on the likelihood of extreme realizations of inflation. Caplet prices tend to be 
low for the intermediate level of $\beta$ while they are higher for extreme levels. We will analyze and discuss this U-shaped pattern of caplet prices with respect to $\beta$ further in section 4.2.3.

\subsubsection{Floorlet prices}

As in the case of caplet prices, differences in target model and B\&S floorlet prices result from different probabilities of extreme realizations of inflation. Table II reports floorlet prices for the same strike prices, levels of volatility, and maturities as in Table I. Since very low levels of inflation are relatively less likely under the target model, target model floorlet prices for low strike prices are much lower than B\&S prices. For example, for a strike price of 1.01 the target model 1-year price $(\sigma=2 \%)$ is 0.18 compared to a B\&S price of 0.38 . For a 3-year floorlet with a strike price of 1.01 and $\sigma=2 \%$ the target model price is close to zero compared to a $\mathrm{B} \& \mathrm{~S}$ price of 0.10 .

Another difference between target model and $B \& S$ prices can be the effect that maturity has on floorlet prices. The effect of maturity can be ambiguous since there are two opposing effects at work when maturity increases. First, if the $C P I$ is expected to increase over the life of the contract (if inflation has a positive drift), a longer maturity reduces the probability of the $C P I$ lying below the strike price at maturity, thus reducing the floorlet price. Second, as maturity increases, the volatility of $C P I$ realizations at maturity increases, resulting in a higher probability of lying below the target and increasing the floorlet price. The ambiguity in the overall effect is reflected in the B\&S prices for a strike price of 1.01. If volatility is low (positive drift dominates), the floorlet price decreases with maturity (0.38 and 0.10), while the price increases with maturity (1.86 and 1.88) if volatility is high (higher long-term volatility dominates).

In contrast, in the target model floorlet prices decrease with maturity for both low and high levels of volatility. The reason is that inflation targeting results in lower levels of long-term $C P I$ volatility, making extremely low realizations of inflation less likely than they are in the B\&S model. Even if instantaneous volatility is high, central bank policy interventions will make it very unlikely that the $C P I$ will lie far below the target zone boundary. For a strike price of 1.01 floorlet prices decrease with maturity even for high levels of volatility, for which 
target model prices are equal to 0.77 (1 year) and 0.16 (3 years).

Valuation of floorlets is important since most inflation linked bonds include a capital protection guarantee so that the payoff at maturity is at least equal to the nominal face value of the bond. This is true in particular for long-dated floorlets with low strike prices that are embedded in e.g. US TIPS, making differences in out-of-the-money floorlet prices across models significant. A nominal guarantee translates into a floorlet with a strike price of 1.00 . In the target zone model it is extremely unlikely for the $C P I$ to lie below this level after several years. For example, for a strike price of 1.01 the 3 -year floorlet price $(\sigma=6 \%)$ is 0.16 while the $\mathrm{B} \& \mathrm{~S}$ price is equal to 1.88 .

We also find an effect of $\beta$, the parameter governing the decay of the effect of past deviations of inflation on current policy. As in the case of caplets, relative differences in prices are larger for options that derive value from more extreme inflation outcomes. The effect of $\beta$ is thus larger for lower strike prices and for longer maturities.

To summarize, we find important differences between model prices and B\&S prices and intuitive effects of target model parameters on model prices. We demonstrate that model prices better predict market prices in section 4.3 .

\subsubsection{The effects of $\alpha$ and $\beta$}

The effectiveness of the central bank's policy in response to deviations from the target $(\alpha)$ and decay of the effect of past inflation deviations on current policy $(\beta)$ are both important determinants of the inflation process and are both innovations of our model compared to previous studies. We therefore briefly examine their effects on prices. We consider 1-year maturity caplet and floorlet prices. The strike price is set equal to 1.02 (equal to the midpoint of the target zone) and the volatility is $6 \%$. The other parameters $(\gamma$ and $\delta)$ are set equal to their base case values.

Figures 1 and 2 plot caplet and floorlet prices for different values of $\alpha$ and $\beta$ (as before $\beta_{1}=\beta_{2}$ ). Option premia are substantially lower for higher levels of $\alpha$. As the parameter increases, volatility outside of the target zone decreases. A high $\alpha$ therefore reduces the probability of extreme and extended levels of inflation outside of the target zone and option 
prices are lower.

Consistent with the patterns in Tables I and II there is a U-shaped relationship between option prices and $\beta$. Initially, as $\beta$ increases, the option price decreases since for a low level of $\beta$ the inflation state variable depends on several observations in the past. In this case there is a significant lag between inflation deviations from the target and changes in the inflation process. For example, even if the current observed inflation is above the target, previous low levels of inflation may mean that the central bank continues to pursue a loose policy that increases inflation. As $\beta$ increases, the speed of the reaction increases and the process becomes more mean reverting due to a faster policy response. Correspondingly, option prices decrease. For high levels of $\beta$ option values start to increase again since the inflation state variable depends mainly on the most recent deviation from the target. In this case the likelihood of several deviations above the target is higher than if the central bank becomes more aggressive in response to continued deviations from the target.

\subsection{Fitting the target model to data}

We now examine the ability of our model to match market prices of inflation options. We use the target model to price US inflation caps with different maturities and strike prices. An inflation cap, the standard inflation contract, is a portfolio of year-on-year (YoY) caplets, each of which is relevant for a different 1-year period over the life of the contract. For example, if the maturity of the cap is equal to 5 years and the strike price is 1.02 , then at the end of each year during which the yearly inflation rate lies above two percent the cap pays the difference. The price of the cap is thus equal to

$$
\operatorname{Cap}(t)=E_{t}^{Q}\left[\sum_{s=1}^{\tau} e^{-\int_{t}^{s} r_{f u} d u}\left(\frac{C P I_{s}}{C P I_{s-1}}-(1+K)\right)^{+}\right]
$$

where $\tau$ is the maturity of the cap. ${ }^{5}$

We fit the target model to market data and then illustrate its ability to capture variation in

\footnotetext{
${ }^{5}$ We note that the contract is not a long-dated cap, as we analyzed in Table I, but rather a portfolio of year-on-year caplets.
} 
cap prices by comparing inflation cap market prices (from Bloomberg) to target model prices. We consider cap prices for three maturities (5, 7, and 10 years) and five strike prices (1.00, $1.01,1.02,1.03$, and 1.04). The set of strike prices is close to symmetric around the mid-point of the target and therefore represents the most liquid contracts. Cap premia are reported in Table III (Panel A). Option premia increase with maturity; a longer maturity means that the cap includes more individual caplets. For example, as a percentage of par, a 5-year cap with a strike price of 1.02 has a premium of $6.28 \%$ while a 10 -year cap with the same strike price has a premium of $14.93 \%$.

Two other inputs necessary to calculate target model prices are nominal interest rates (swap rates) and zero coupon inflation swap rates; we collect both data series from Bloomberg. We report the term structures of nominal swap rates and zero coupon inflation rates in Table IV. From the nominal swap rates we calculate spot rates (zero coupon rates), which we use to discount the caplet prices. From the zero coupon inflation swap rates we calculate forward inflation drifts (the difference between the forward nominal and real rates), which we need in order to simulate paths for inflation under the model assumptions.

The final input needed to calculate predicted prices in the target model are data on past inflation rates, which are needed since the inflation state variable depends on the weighted deviations from the target. We collect data on inflation (changes in the CPI) from the Bureau of Labor Statistics (BLS) and set the target equal to $M=1.75 \%$ (according to the Federal Open Market Committee, the implicit target zone is limited to the range between $1.5 \%$ and $2 \%$ ). Figure 3 plots the annual inflation rate from May 2008 to April 2010, the 24 months previous to the date at which we price the options, along with the mid-point of the target. We choose a period of 24 months over which to measure past deviations from the target since the conventional assumption is that there is a 2 year lag between the enactment of monetary policy and the realization of the full effect on the economy. We assume that the inflation state variable is constructed using a weighted average of inflation deviations over this period. ${ }^{6}$

\footnotetext{
${ }^{6}$ We assume that inflation is observed instantaneously. We note, however, that in practice there is a 2-month reporting lag in the US. This leads to institutional consequences regarding option prices: for example, the payoff of a 1-year option is based on realized inflation over the 12-month period beginning two month previous to the start of the contract and ending two months before maturity. Given the
} 
In the US there are no explicitly boundaries for the inflation target zone. This means that $\delta_{1}=\delta_{2}$ and $\gamma_{1}=\gamma_{2}$. In order to make the parameter space more manageable we also assume that $\beta_{1}=\beta_{2}$. The parameter space is thus given by $(\alpha, \beta, \gamma, \delta, \sigma)$. We note that, assuming no difference in the marginal effect of inflation deviations inside and outside the target zone means that the parameter $z$ (the distance between the target and the boundary of the target zone) has no effect.

We find model parameters that best fit the observed data. We implement a numerical search over a large parameter space using the sampling method proposed by Sobol (1967). For each market price, we calculate the pricing error as the difference between the market price and the model price, $P^{\text {Model }}-P^{\text {Market }}$. For each set of parameters we then calculate the total absolute error:

$$
T A E=\sum_{i=1}^{N}\left|P^{\text {Model }}-P^{\text {Market }}\right| .
$$

The parameter combination that minimizes the total absolute error is: $\alpha=204, \beta=23$, $\gamma=0.015, \delta=1.34$, and $\sigma=3.63 \%$.

Given that our model reflects central bank behavior we can interpret the parameters: Inflation below the target results in stronger central bank reaction than inflation above the target $(\delta>\gamma)$, consistent with a preference for a low probability of deflation by the Federal Reserve. ${ }^{7}$ These parameters are also consistent with forward inflation drift levels above $2 \%$, which are present in the inflation swap data reported in Table IV. Also, inflation is expected to be quite variable close to the target $(\sigma=3.63 \%)$, but deviations from the target result in policy that ensures a return to the target ( $\alpha$ is large). Lastly, since $\beta$ is large (the pricing error does not increase with $\beta$ ), the inflation state variable depends mainly on recent deviations from the target.

longer maturities of the contracts we consider, the effect of abstracting from this effect will be small.

${ }^{7}$ Williams (2009) points out that "Forecasters appear to be convinced that the Federal Reserve would not be content with sustained deflation and would take policy actions to restore a positive rate of inflation." 


\subsubsection{Comparing market, target model, and Black-Scholes option prices}

Table III reports market prices (Panel A), differences between target model and market prices (Panel B), and differences between Black and Scholes (1973) and market prices (Panel C). We report pricing errors $\left(P^{\text {Model }}-P^{\text {Market }}\right)$ for each of the 15 options, and total absolute pricing errors for each strike price and maturity. The total absolute error of the target model is $4.1 \%$, while the total absolute error for the $\mathrm{B} \& \mathrm{~S}$ model is $7.7 \%$, which means that using the target model results in a $47 \%$ decline in pricing error relative to B\&S. We can also calculate the percentage absolute error by normalizing by the average option market price. The average absolute error is equal to $2.4 \%$, while the B\&S error is equal to $4.5 \%{ }^{8}$

We report total pricing errors across different strike prices and different maturities. For each strike price and for each maturity the target model outperforms B\&S. Given the intuition of inflation targeting, we expect the target model to be important in particular for option prices that derive value from levels of inflation with large differences relative to the target. It is these prices that in the calibration analysis (Section 4.2) we found to have the largest differences from B\&S model prices. Consistent with those patterns, we find that the target model performs well relative to $B \& S$ specifically for caps with extreme strike prices: the average total pricing error is $0.65 \%$ for strike prices equal to 1.00 and 1.04 compared to a pricing error of $2.04 \%$ for B\&S. As expected, the outperformance of the target model is smaller for strike prices that are closer to the target of $1.75 \%$ : Total target model absolute errors for options with strike prices equal to $1.01,1.02$, and 1.03 is $0.94 \%$, closer to the level of $1.21 \%$ for B\&S. The target model also performs better relative to B\&S for longer-dated options: For 5-year options the difference in error between the two models is $0.59 \%$ while it is equal to $1.82 \%$ for 10 -year caps.

Another way to capture the ability of the model to match market prices is to calculate Black and Scholes (1973) implied volatility. Table V reports implied volatilities for market prices (Panel A) and for target model prices (Panel B). For all three maturities, levels of implied volatility for market prices are different across strike prices and are lower for lower strike prices. Option market prices thus exhibit the common pattern of a volatility 'smile' or

\footnotetext{
${ }^{8}$ A lower pricing error may not be surprising given that the target model is more flexible and contains the Black and Scholes (1973) model as a special case.
} 
'skew.' We find that the target model captures the observed pattern in implied volatility.

\subsubsection{Model prices when inflation is mean-reverting Vasicek (1977) or when volatility is stochastic (Hull and White, 1988; Heston, 1993)}

We compare target model pricing errors to two additional models. First we consider, a meanreverting (Vasicek, 1977) model, which is a special case of our target model when imposing the restrictions that $\delta_{1}=\delta_{2}=\gamma_{1}=\gamma_{2}, \alpha=0$, and $\beta_{1}=\beta_{2} \approx \infty$. In this case the parameter space is reduced to $(\gamma, \sigma)$. A search for parameters that best fit the market data (Table III) results in a level of $\gamma=0$, which reduces the model to the Black and Scholes (1973) case of no mean reversion. Thus absolute pricing errors are not reduced by allowing the possibility of Vasicek model mean reversion.

Second, we implement a model with stochastic volatility. Following Hull and White (1988) and Heston (1993) we calculate model prices in a model where volatility is stochastic. In contrast to our model, the Hull and White (1988) and Heston (1993) stochastic volatility models are two factor models in which one stochastic process is used for the dynamics of the underlying asset (inflation) and the second for the volatility of volatility. Specifically, the processes of the inflation index and its return volatility are given by:

$$
\begin{aligned}
& \frac{d P_{t}}{P_{t}}=\left(r_{f}-r_{r}\right) d t+\sqrt{\nu_{t}} d W_{P} \\
& \frac{d \nu_{t}}{\nu_{t}}=\eta\left(\theta-\nu_{t}\right) d t+\xi \sqrt{\nu_{t}} d Z_{P}
\end{aligned}
$$

where $d W_{P}$ and $d Z_{P}$ are two standard Wiener processes with correlation $\rho, \xi$ is the instanta-

neous standard deviation of $\frac{d \nu_{t}}{\nu_{t}}$, and the mean reversion speed of the volatility to its long run mean, $\theta$, is denoted by $\eta$.

We implement the model assuming that the current level of volatility is equal to its long run mean. We then search for parameters that minimize the total absolute pricing error, which we find to be equal to $4.74 \%$. The stochastic volatility model thus results in a substantially lower pricing error than the Black and Scholes (1973) and Vasicek (1977) models (both 7.7\%) 
and is only slightly larger than the target model pricing error of $4.1 \% .^{9}$ Our proposed target model therefore has the benefit of incorporating the intuition of inflation targeting while not suffering from a decline in pricing accuracy compared to other models.

\section{Conclusion}

In this paper we present a flexible model for the valuation of inflation derivatives under an inflation target regime. The central bank may choose to intervene to keep inflation realizations within a fixed target zone. However, the effectiveness of such intervention may be imperfect, allowing deviations of inflation from the target zone.

In each period the intervention of the central bank to steer inflation towards the target depends on the economy's past record of deviations from the target. This record is captured by a state variable that accumulates the weighted past deviations from the target. Large deviations, recent deviations, and ongoing deviations lead to more aggressive central bank action and a stronger tendency of inflation to revert back to the target. Our model can accommodate a large number of inflation target regimes: it can capture different reactions to previous deviations, different responses to deviations inside and outside the target zone, different responses to inflation above and below the target, and different levels of policy effectiveness.

We use our model to price inflation options. Differences between target model and Black and Scholes (1973) prices are high in particular for options that are sensitive to extreme realizations of inflation. For example, prices of high strike price caplets are significantly smaller than B\&S prices because the probability of very high levels of inflation is much lower when taking into account the reaction of the central bank. Long-dated floorlet prices with low strike prices have lower prices in the target model (as compared to B\&S), since continued levels of low inflation are less likely given central bank intervention. Since low-strike long-dated floorlets

\footnotetext{
${ }^{9}$ We implement the stochastic volatility model as follows: Following Broadie and Kaya (2006) we simulate a path for volatility and then use the Hull and White (1988) approximation to calculate the value of each forward starting caplet that is part of the cap. We note that several other authors including Van Haastrecht and Pelsser (2010) and Kahl and Jackel (2006) have also contributed towards developing efficient discretization schemes for the Heston (1993) model.
} 
are embedded in e.g. TIPS, the price differences take on added importance.

Fitting our model to US inflation caps we find that the target model is able to reduce the pricing error of the B\&S model by close to $50 \%$. Predicted prices are more accurate for all strike prices and maturities. Consistent with the target model being better able to predict extreme events, the outperformance of the model relative to $\mathrm{B} \& \mathrm{~S}$ is largest for longer-dated options and for options with strike prices outside of the target zone. 


\section{Bibliography}

Avriel, M., Bar Shavit., P., \& Reisman, H. (1988). Pricing currency options in the presence of a target zone. Working paper, Technion - Israel Institute of Technology.

Ball, C., \& Roma, M. (1994). Target zone modeling and estimation for European Monetary System exchange rates. Journal of Empirical Finance, 1, 385-420.

Belgrade, N., Benhamou, E., \& Koehler, E. (2004). A market model for inflation. SSRN working paper.

Bhansali, V., Dorsten, M., \& Wise, M. (2009). Asymmetric monetary policy and the yield curve. Journal of International Money and Finance, 28, 1408-1425.

Black, F., \& Scholes, M. (1973). The pricing of options and corporate liabilities. Journal of Political Economy, 81, 637-659.

Bodie, Z. (1990). Inflation insurance. Journal of Risk and Insurance, 57, 634-645.

Broadie, M., \& Kaya, O. (2006). Exact simulation of stochastic volatility and other affine jump diffusion models. Operations Research, 54, 217-231.

Christensen, P.O., Lando, D., \& Miltersen, K.R. (1998). State dependent realignments in target zone currency regimes. Review of Derivatives Research, 1, 295-323.

De Jong, F., Drost, F.C., \& Werker, B.J.M. (2001). A jump-diffusion model for exchange rates in a target zone. Statistica Neerlandica, 55, 270-300.

Dumas, B., Jennergren L.P., \& Näslund, B. (1993). Currency option pricing in credible target zones. Review of Futures Markets, 12, 323-340.

Dumas, B., Jennergren, L.P., \& Näslund, B. (1995). Realignment risk and currency option pricing in target zone. European Economic Review, 39, 1523-1544.

Garman, M. B., \& Kohlhagen, S. W. (1983). Foreign currency option values. Journal of International Money and Finance, 2, 231-237.

Haastrecht, A. van, \& Pelsser., A. (2010). Efficient, almost exact simulation of the Heston stochastic volatility model. International Journal of Theoretical and Applied Finance, $31,1-43$.

Haastrecht, A. van, \& Pelsser, A. (2011). Generic pricing of FX, inflation and stock options under stochastic interest rates and stochastic volatility. Quantitative Finance, 11, 665691.

Heath, D., Jarrow, R., \& Morton, A. (1992). Bond pricing and the term structure of interest rates: A new methodology for contingent claim valuation. Econometrica, 60, 77-105.

Heenan, G., Peter, M., \& Roger, S. (2006). Implementing Inflation Targeting: Institutional Arrangements, Target Design, and Communications. Working Paper, IMF. 
Heston, S.L. (1993). A Closed Form Solution for Options with Stochastic Volatility with Applications to Bond and Currency Options. Review of Financial Studies, 6, 327-344.

Hinnerich, M. (2008). Inflation indexed swaps and swaptions, Journal of Banking and Finance, $32,2293-2306$.

Hull, J., \& White, A. (1988). An Analysis of the Bias in Option Pricing Caused by a Stochastic Volatility. Advances in Futures and Options Research. Greenwich, CT: JAI Press.

Jarrow, R., \& Yildirim, Y. (2003). Pricing TIPS and related derivative securities using an HJM model. Journal of Financial and Quantitative Analysis, 38, 337-358.

Kahl, C., \& Jackel, P. (2006). Fast strong approximation Monte Carlo schemes for stochastic volatility models. Quantitative Finance, 6, 513-536.

Kenyon, C. (2008). Inflation is normal. Risk.net.

Krugman, P. (1991). Target zone and exchange rate dynamics. Quarterly Journal of Economics, 106, 669-682.

Kydland, F.E., \& Prescott, E.C. (1977). Rules rather than discretion: The inconsistency of optimal plans. Journal of Political Economy, 85, 473-492.

Larsen, K.S., \& Sorensen, M. (2007). A diffusion model for exchange rates in a target zone. Mathematical Finance, 17, 285-306.

Lioui, A., \& Poncet, P. (2005). General equilibrium pricing of CPI's derivatives. Journal of Banking and Finance, 29, 1265-1294.

Mankiw, N.G. (2002). US monetary policy during the 1990s. In J. Frankel \& P. Orszag, (Eds.), American Economic Policy in the 1990s. Cambridge, MA: MIT Press.

Meltzer, A.H. (2010). Politics and the Fed. Journal of Monetary Economics, 58, 39-48.

Mercurio, F. (2005). Pricing inflation-indexed derivatives. Quantitative Finance, 5, 289-302.

Mercurio, F., \& Moreni, N. (2006). Inflation with a smile. Risk, 19, 70-75.

Roger, S., \& Stone, M. (2005). On target? The international experience with achieving inflation targets. Working Paper, IMF.

Rogoff, K. (1985). The optimal degree of commitment to an intermediate monetary target. Quarterly Journal of Economics, 100, 1169-1189.

Sobol, I. M. (1967). The distribution of points in a cube and the approximate evaluation of integrals. USSR Computational Math and Math. Physics, 19, 86-112.

Svensson, L.E.O. (1993). Stochastic devaluation risk and the empirical fit of target zone. Journal of Monetary Economics, 28, 87-116. 
Svensson, L.E.O. (1997). Inflation forecast targeting: Implementing and monitoring inflation targets. European Economic Review, 41, 1111-1146.

Svensson, L.E.O. (2000). Open-economy inflation targeting. Journal of International Economics, 50, 155-183.

Taylor, J.B. (1993). Discretion versus policy rules in practice. Carnegie-Rochester Conference Series on Public Policy, 39, 195-214.

Vasicek, O. (1977). An equilibrium characterization of the term structure. Journal of Financial Economics, 5, 177-188.

Williams, J.C. (2009). The Risk of Deflation. FRBSF Economic Letters 2009-12. 
TABLE I

Caplet valuation for different strikes, maturities, and model parameters

Panel A: Maturity is equal to one year

\begin{tabular}{|c|c|c|c|c|c|c|c|}
\hline & \multirow[b]{2}{*}{ Model } & \multirow[b]{2}{*}{$\beta$} & \multicolumn{5}{|c|}{ Strike price } \\
\hline & & & 0.99 & 1.01 & 1.02 & 1.03 & 1.05 \\
\hline \multirow{4}{*}{$\sigma=2 \%$} & \multirow{3}{*}{$\begin{array}{l}\text { Target } \\
\text { Model }\end{array}$} & $\beta=0$ & 2.85 & 1.14 & 0.57 & 0.20 & 0.00 \\
\hline & & $\beta=3.0$ & 2.84 & 1.12 & 0.54 & 0.18 & 0.00 \\
\hline & & $\beta \rightarrow \infty$ & 2.85 & 1.16 & 0.59 & 0.22 & 0.00 \\
\hline & $B \& S$ & & 2.93 & 1.35 & 0.78 & 0.40 & 0.07 \\
\hline \multirow{4}{*}{$\sigma=6 \%$} & \multirow{3}{*}{$\begin{array}{l}\text { Target } \\
\text { Model }\end{array}$} & $\beta=0$ & 3.02 & 1.80 & 1.30 & 0.87 & 0.23 \\
\hline & & $\beta=3.0$ & 2.94 & 1.66 & 1.16 & 0.73 & 0.14 \\
\hline & & $\beta \rightarrow \infty$ & 3.10 & 1.89 & 1.40 & 0.96 & 0.31 \\
\hline & $B \& S$ & & 4.01 & 2.83 & 2.33 & 1.90 & 1.21 \\
\hline
\end{tabular}

Panel B: Maturity is equal to three years

\begin{tabular}{|c|c|c|c|c|c|c|c|}
\hline & \multirow{2}{*}{ Model } & \multirow{2}{*}{$\beta$} & \multicolumn{5}{|c|}{ Strike price } \\
\hline & & & 1.01 & 1.03 & 1.06 & 1.09 & 1.11 \\
\hline \multirow{4}{*}{$\sigma=2 \%$} & \multirow{3}{*}{$\begin{array}{l}\text { Target } \\
\text { Model }\end{array}$} & $\beta=0$ & 4.40 & 2.70 & 0.74 & 0.05 & 0.00 \\
\hline & & $\beta=3.0$ & 4.40 & 2.71 & 0.72 & 0.05 & 0.00 \\
\hline & & $\beta \rightarrow \infty$ & 4.41 & 2.76 & 0.86 & 0.11 & 0.01 \\
\hline & $B \& S$ & & 4.56 & 3.07 & 1.34 & 0.42 & 0.15 \\
\hline \multirow{4}{*}{$\sigma=6 \%$} & \multirow{3}{*}{$\begin{array}{l}\text { Target } \\
\text { Model }\end{array}$} & $\beta=0$ & 4.46 & 3.07 & 1.48 & 0.53 & 0.21 \\
\hline & & $\beta=3.0$ & 4.46 & 3.03 & 1.41 & 0.48 & 0.19 \\
\hline & & $\beta \rightarrow \infty$ & 4.68 & 3.36 & 1.82 & 0.83 & 0.43 \\
\hline & $B \& S$ & & 6.35 & 5.26 & 3.86 & 2.75 & 2.15 \\
\hline
\end{tabular}

Note. This table presents the value of caplets (as percentage of notional amount) for various strike prices. The CPI is normalized to 1 and the time to maturity is equal to one year (Panel A) and three years (Panel B). The nominal interest rate is fixed and equal to $r_{f}=5 \%$, the real rate is set equal to $r_{r}=3 \%$, the volatility of the CPI is equal to $\sigma=2 \%$ or $\sigma=6 \%$. The midpoint of the inflation target zone is $2 \%$, the target zone is symmetric around the midpoint with a range between the midpoint and the boundary of $z=1 \%$, and inflation is equal to the target previous to the valuation date. Inflation state variable parameters are given by: $\alpha=40, \gamma_{1}=\delta_{1}=0.3, \gamma_{2}=\delta_{2}=0.6$. The time decay parameters $\beta_{1}$ and $\beta_{2}$ are set equal to 0,3 , and $\infty$. 
TABLE II

Floorlet valuation for different strikes, maturities, and model parameters

Panel A: Maturity is equal to one year

\begin{tabular}{|c|c|c|c|c|c|c|c|}
\hline & \multirow[b]{2}{*}{ Model } & \multirow[b]{2}{*}{$\beta$} & \multicolumn{5}{|c|}{ Strike price } \\
\hline & & & 0.99 & 1.01 & 1.02 & 1.03 & 1.05 \\
\hline \multirow{4}{*}{$\sigma=2 \%$} & \multirow{3}{*}{$\begin{array}{l}\text { Target } \\
\text { Model }\end{array}$} & $\beta=0$ & 0.00 & 0.20 & 0.58 & 1.17 & 2.86 \\
\hline & & $\beta=3.0$ & 0.00 & 0.18 & 0.55 & 1.14 & 2.86 \\
\hline & & $\beta \rightarrow \infty$ & 0.00 & 0.22 & 0.60 & 1.18 & 2.87 \\
\hline & $B \& S$ & & 0.06 & 0.38 & 0.76 & 1.33 & 2.90 \\
\hline \multirow{4}{*}{$\sigma=6 \%$} & \multirow{3}{*}{$\begin{array}{l}\text { Target } \\
\text { Model }\end{array}$} & $\beta=0$ & 0.23 & 0.91 & 1.36 & 1.88 & 3.15 \\
\hline & & $\beta=3.0$ & 0.14 & 0.77 & 1.22 & 1.74 & 3.05 \\
\hline & & $\beta \rightarrow \infty$ & 0.31 & 1.00 & 1.46 & 1.98 & 3.23 \\
\hline & $B \& S$ & & 1.13 & 1.86 & 2.31 & 2.83 & 4.04 \\
\hline
\end{tabular}

Panel B: Maturity is equal to three years

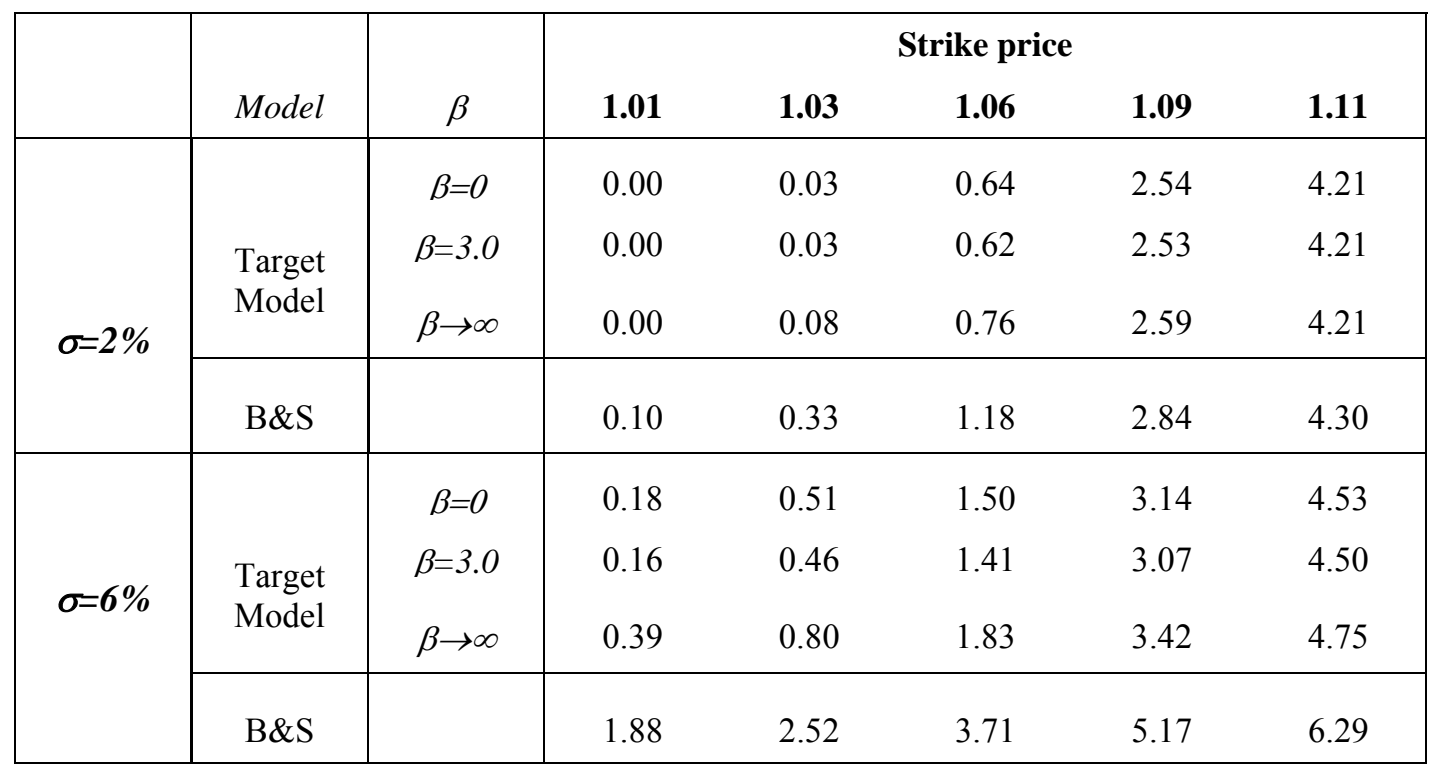

Note. This table reports floorlet prices for different maturities, strike prices, volatilities, and levels of model parameters. The unreported model parameters are the same as in Table 1. 


\section{Table III \\ Market prices and model prices for US inflation caps}

Panel A: Market prices of US inflation caps

\begin{tabular}{|c|c|c|c|c|c|}
\hline & \multicolumn{5}{|c|}{ Strike price } \\
\hline Maturity & $\mathbf{1 . 0 0}$ & $\mathbf{1 . 0 1}$ & $\mathbf{1 . 0 2}$ & $\mathbf{1 . 0 3}$ & $\mathbf{1 . 0 4}$ \\
\hline $\mathbf{5}$ & $13.24 \%$ & $9.46 \%$ & $6.28 \%$ & $3.88 \%$ & $2.30 \%$ \\
\hline $\mathbf{7}$ & $19.63 \%$ & $14.51 \%$ & $10.09 \%$ & $6.61 \%$ & $4.15 \%$ \\
\hline $\mathbf{1 0}$ & $27.88 \%$ & $20.97 \%$ & $14.93 \%$ & $10.05 \%$ & $6.47 \%$ \\
\hline
\end{tabular}

Panel B: Differences between US inflation cap target model and market prices

\begin{tabular}{|c|c|c|c|c|c|c|}
\hline & \multicolumn{5}{|c|}{ Strike price } & \\
\hline Maturity & $\mathbf{1 . 0 0}$ & $\mathbf{1 . 0 1}$ & $\mathbf{1 . 0 2}$ & $\mathbf{1 . 0 3}$ & $\mathbf{1 . 0 4}$ & TAE \\
\hline $\mathbf{5}$ & $0.44 \%$ & $0.03 \%$ & $0.29 \%$ & $0.51 \%$ & $0.47 \%$ & $1.74 \%$ \\
\hline $\mathbf{7}$ & $0.13 \%$ & $-0.43 \%$ & $-0.18 \%$ & $0.11 \%$ & $0.16 \%$ & $1.00 \%$ \\
\hline $\mathbf{1 0}$ & $0.07 \%$ & $-0.68 \%$ & $-0.46 \%$ & $-0.13 \%$ & $-0.02 \%$ & $1.35 \%$ \\
\hline TAE & $0.64 \%$ & $1.14 \%$ & $0.93 \%$ & $0.74 \%$ & $0.65 \%$ & $\underline{\mathbf{4 . 1 0} \%}$ \\
\hline
\end{tabular}

Panel C: Differences between US inflation cap B\&S and market prices

\begin{tabular}{|c|c|c|c|c|c|c|}
\hline & \multicolumn{5}{|c|}{ Strike price } & \\
\hline Maturity & $\mathbf{1 . 0 0}$ & $\mathbf{1 . 0 1}$ & $\mathbf{1 . 0 2}$ & $\mathbf{1 . 0 3}$ & $\mathbf{1 . 0 4}$ & TAE \\
\hline $\mathbf{5}$ & $-0.34 \%$ & $0.11 \%$ & $0.52 \%$ & $0.71 \%$ & $0.64 \%$ & $2.33 \%$ \\
\hline $\mathbf{7}$ & $-1.02 \%$ & $-0.52 \%$ & $-0.02 \%$ & $0.29 \%$ & $0.34 \%$ & $2.20 \%$ \\
\hline $\mathbf{1 0}$ & $-1.56 \%$ & $-1.02 \%$ & $-0.43 \%$ & $0.00 \%$ & $0.16 \%$ & $3.17 \%$ \\
\hline TAE & $2.92 \%$ & $1.65 \%$ & $0.97 \%$ & $1.00 \%$ & $1.15 \%$ & $\underline{\mathbf{7 . 7 0} \%}$ \\
\hline
\end{tabular}

Note. This table reports market prices (Panel A) and differences between market prices and model prices (Panels B and C) for US CPI inflation caps. Prices are reported as a percentage of notional, for various strike prices and maturities; prices are from April 30, 2010; the data source is Bloomberg. Panel B reports differences between target model and market prices as well as total absolute errors (TAE) for each group of strike prices and maturities. The parameters for the target model are: $\sigma=3.63 \%, \alpha=214, \beta_{1}=\beta_{2}=22.8, \gamma_{1}=\gamma_{2}=0.02$ and $\delta_{1}=\delta_{2}=1.34$. Panel C reports differences between Black and Scholes (1973) model and market prices. Volatility is set equal to $\sigma=3.13 \%$. Inflation and interest rate data are reported in Table 4 and Figure 3. 


\section{Table IV \\ US nominal interest rate and zero coupon inflation swap rates}

\begin{tabular}{|c|c|c|}
\hline Years & $\begin{array}{c}\text { Nominal } \\
\text { swap rates }\end{array}$ & $\begin{array}{c}\text { Inflation ZC } \\
\text { swap rates }\end{array}$ \\
\hline 1 & $1.02 \%$ & $1.38 \%$ \\
\hline 2 & $1.20 \%$ & $1.74 \%$ \\
\hline 3 & $1.73 \%$ & $1.99 \%$ \\
\hline 4 & $2.21 \%$ & $2.17 \%$ \\
\hline 5 & $2.61 \%$ & $2.29 \%$ \\
\hline 6 & $2.93 \%$ & $2.44 \%$ \\
\hline 7 & $3.18 \%$ & $2.55 \%$ \\
\hline 8 & $3.37 \%$ & $2.65 \%$ \\
\hline 9 & $3.53 \%$ & $2.71 \%$ \\
\hline 10 & $3.66 \%$ & $2.77 \%$ \\
\hline
\end{tabular}

Note. This table reports the term structure of US nominal interest rate swap rates and the term structure of zero coupon (ZC) inflation swap rates for April 30, 2010. The data are used to calculate option premia (see Table 3). The data source is Bloomberg. 
TABLE V

Black and Scholes implied volatilities for market prices and target model prices

Panel A: Implied B\&S volatility for market prices

\begin{tabular}{|c|c|c|c|c|c|}
\hline & \multicolumn{5}{|c|}{ Strike price } \\
\hline Maturity & $\mathbf{1 . 0 0}$ & $\mathbf{1 . 0 1}$ & $\mathbf{1 . 0 2}$ & $\mathbf{1 . 0 3}$ & $\mathbf{1 . 0 4}$ \\
\hline $\mathbf{5}$ & $3.36 \%$ & $3.06 \%$ & $2.85 \%$ & $2.74 \%$ & $2.73 \%$ \\
\hline $\mathbf{7}$ & $3.66 \%$ & $3.36 \%$ & $3.14 \%$ & $3.01 \%$ & $2.98 \%$ \\
\hline $\mathbf{1 0}$ & $3.75 \%$ & $3.47 \%$ & $3.26 \%$ & $3.13 \%$ & $3.08 \%$ \\
\hline
\end{tabular}

Panel B: Implied B\&S volatility for the target model

\begin{tabular}{|c|c|c|c|c|c|}
\hline & \multicolumn{5}{|c|}{ Strike price } \\
\hline Maturity & $\mathbf{1 . 0 0}$ & $\mathbf{1 . 0 1}$ & $\mathbf{1 . 0 2}$ & $\mathbf{1 . 0 3}$ & $\mathbf{1 . 0 4}$ \\
\hline $\mathbf{5}$ & $3.65 \%$ & $3.08 \%$ & $3.01 \%$ & $3.02 \%$ & $3.00 \%$ \\
\hline $\mathbf{7}$ & $3.72 \%$ & $3.17 \%$ & $3.07 \%$ & $3.06 \%$ & $3.05 \%$ \\
\hline $\mathbf{1 0}$ & $3.78 \%$ & $3.24 \%$ & $3.12 \%$ & $3.09 \%$ & $3.07 \%$ \\
\hline
\end{tabular}

Note. This table reports levels of Black and Scholes (1973) implied volatilities for market prices from April 30, 2010 (Panel A) and target model prices (Panel B). The target model parameters are those reported in Table 3. 


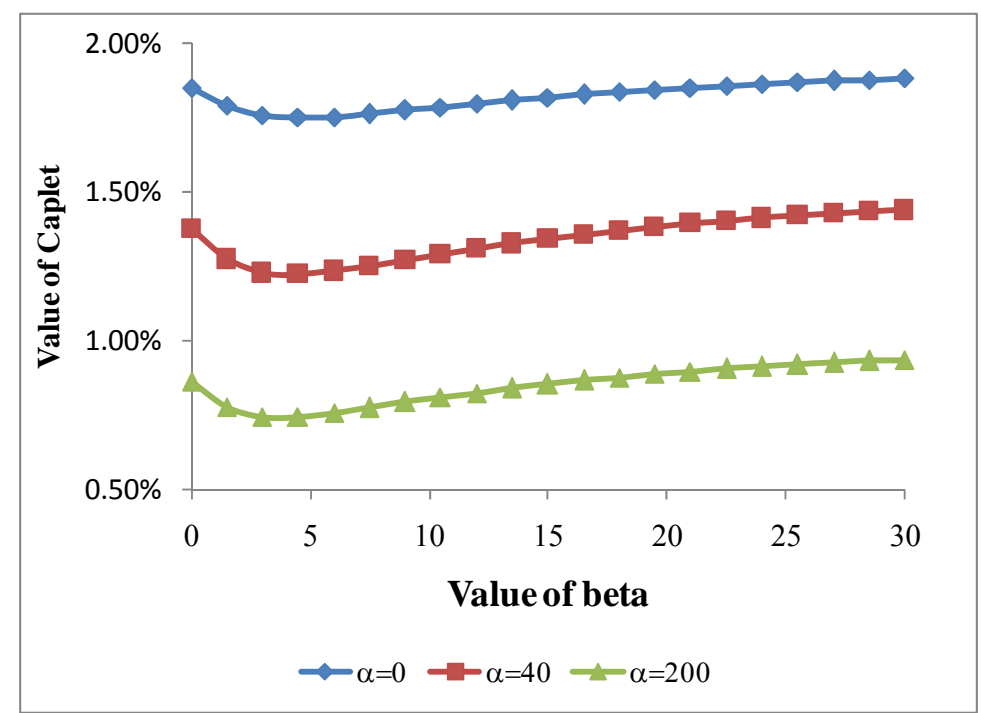

Figure 1

\section{Caplet valuation for different values of the model parameters $\alpha$ and $\beta$}

This figure graphs caplet prices for different levels of $\beta$. The parameter determines the effect of past deviations from the target on the process of inflation (central bank memory). The parameter $\alpha$ determines the rate of decrease of the diffusion term with respect to an increase in the absolute value of the inflation target state variable (policy effectiveness). We set it equal to 0,40 , and 200 . Inflation volatility is equal to $6 \%$, the maturity is 1 year, and the strike price is 1.02 . All other parameters are equal to their base case values. 


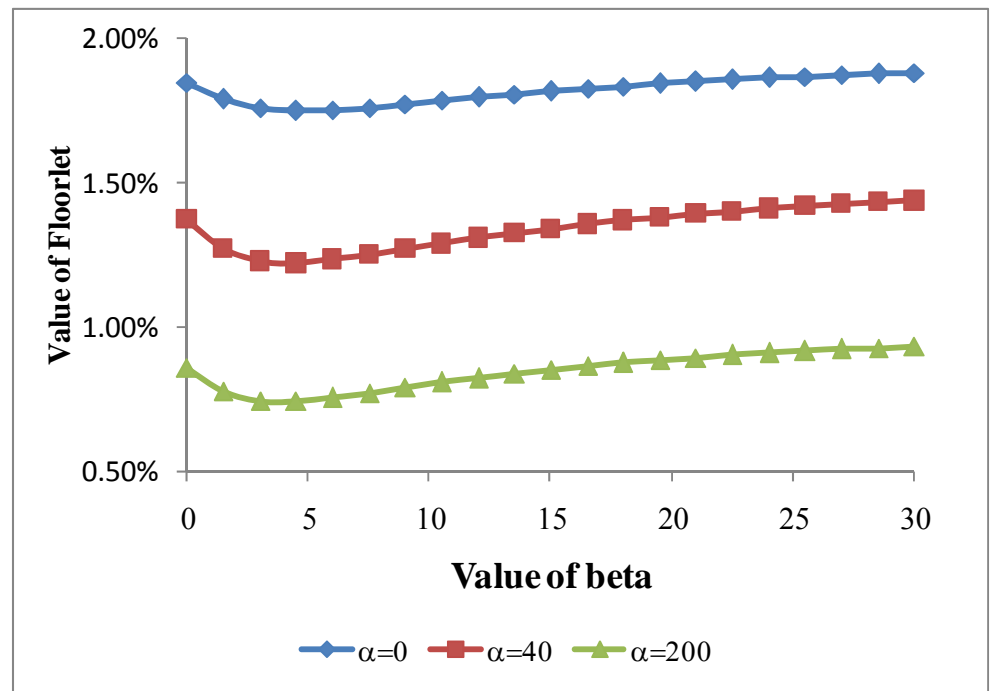

Figure 2

\section{Floorlet valuation for different values of model parameters $\alpha$ and $\boldsymbol{\beta}$}

This figure graphs floorlet prices for different levels of $\beta$. The parameter determines the effect of past deviations from the target on the process of inflation (central bank memory). The parameter $\alpha$ determines the rate of decrease of the diffusion term with respect to an increase in the absolute value of the inflation target state variable (policy effectiveness). We set it equal to 0,40 , and 200 . Inflation volatility is equal to $6 \%$, the maturity is 1 year, and the strike price is 1.02. All other parameters are equal to their base case values. 


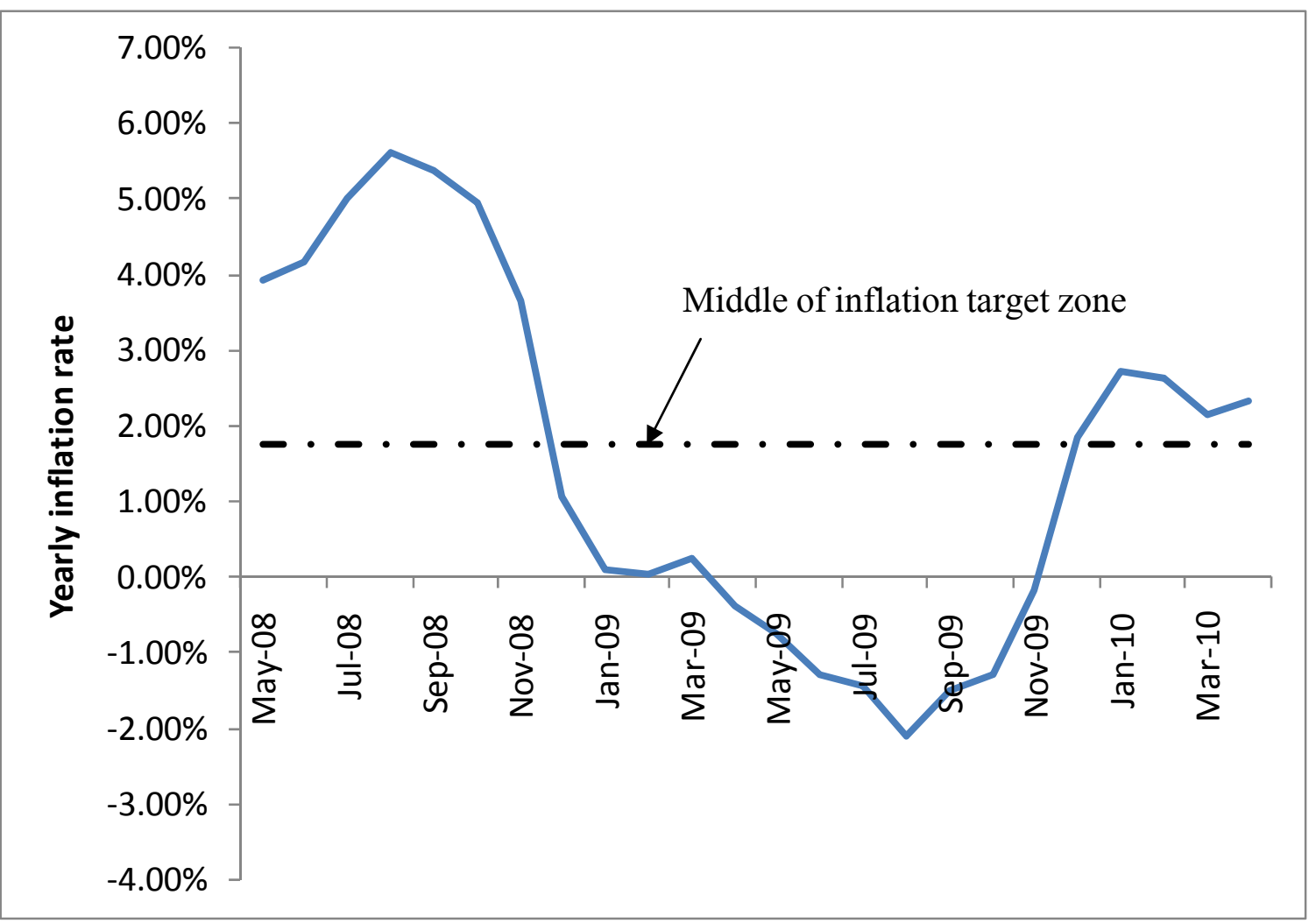

Figure 3

US inflation and inflation target

This figure graphs the annual inflation rate for the US from May 2008. Annual inflation is calculated from the Bureau of Labor Statistics (BLS) data for the CPI. According to the FOMC (http://www.federalreserve.gov) the middle of inflation target zone (the target inflation rate) is equal to $1.75 \%$. 